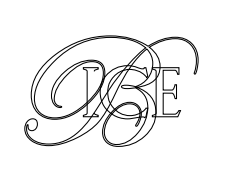

\title{
LA COBERTURA DE LOS RIESGOS DE LA INTERNACIONALIZACIÓN EN 2015 Y 2016
}

La Ley 8/2014, de 22 de abril, sobre cobertura por cuenta del Estado de los riesgos de la internacionalización de la economía española, estableció un nuevo marco jurídico en el que se desenvuelve el apoyo oficial a la actividad del seguro de crédito a la exportación. Garantiza que nuestros exportadores e inversores cuenten con condiciones tan competitivas como las de sus competidores en los mercados internacionales.

Los datos de cobertura por cuenta del Estado en el bienio 2015-2016 ponen de manifiesto que se ha producido una transición armoniosa al nuevo marco legislativo y que la actividad aseguradora, si bien se ha reducido sensiblemente en comparación con el periodo de crisis financiera, se encuentra en la actualidad en niveles que podemos considerar normales y en línea con la tendencia que muestran los datos agregados de la Unión de Berna.

Palabras clave: España, seguros a la exportación, cuenta del Estado, CESCE.

Clasificación JEL: F10, F19, G22, G28.

\section{Introducción}

La cobertura por cuenta del Estado de los riesgos de la internacionalización, realizada por medio de los distintos instrumentos de seguro o garantía que permite la normativa vigente, ha sido desde su creación un instrumento esencial de la política comercial española. A través del mismo, el Estado da cobertura a gran parte de los riesgos asociados a las operaciones de internacionalización, ya sean riesgos de carácter comercial, político o extraordinario. Por otro lado, este tipo de instrumentos tiene como principal ventaja el

\footnotetext{
* Ministerio de Economía, Industria y Competitividad. Versión de marzo de 2018.
}

hecho de que complementa y completa la financiación privada, puesto que se apoya en ella, sirviendo de catalizador de recursos financieros para operaciones de comercio e inversiones en momentos de insuficiencia financiera y, sobre todo, en aquellos países donde la operativa está sujeta a una mayor incertidumbre.

Como instrumento de política comercial, el seguro por cuenta del Estado garantiza que nuestros exportadores e inversores cuenten con condiciones tan competitivas como las de sus competidores en los mercados globales. En este sentido, es esencial que el Estado establezca las condiciones que permitan garantizar lo anterior, compatibilizando este objetivo con la consecución del mayor equilibrio $\triangleright$ 
para el sistema financiero y el menor impacto presupuestario posible.

En un entorno en el que el sector exportador español sigue mostrando gran dinamismo y continúa siendo uno de los motores de crecimiento de la economía española, es esencial que la Administración Pública ofrezca a las empresas españolas que se embarcan en proyectos comerciales o empresariales en el exterior una serie de instrumentos diseñados para facilitar su labor, entre los cuales está el Seguro de Crédito a la Exportación que gestiona la Compañía Española de Seguros de Crédito a la Exportación (de ahora en adelante, CESCE). Bajo este instrumento, el Estado ofrece herramientas para mitigar buena parte de los riesgos que puedan surgir en las distintas fases del proceso de internacionalización, a través de un amplio catálogo de modalidades de seguros o garantías.

El año 2016 ha sido un año relativamente bueno para la cuenta del Estado de CESCE. Tras varios años de actividad atípica, tanto por los máximos históricos registrados en los primeros años de la crisis como por la brusca caída experimentada a continuación, 2015 supuso una vuelta a la normalidad y la contratación en 2016 se ha mantenido en un nivel similar. En lo que respecta a la distribución de la nueva contratación entre las distintas modalidades de seguro, se regresa a un modelo más tradicional, en el que el crédito comprador es el tipo de cobertura más contratada (un 81 por 100 del total, frente a un 34 por 100 en 2012). Así mismo, se observa una menor concentración en un único proyecto, aunque, como suele ser habitual, las mayores operaciones aglutinan una parte importante de la nueva contratación. Un 50 por 100 de toda la contratación del año corresponde a cuatro proyectos en Chile, Perú, Angola y Omán. Por otro lado, las cifras de contratación de avales han seguido cayendo como consecuencia de la reducción de los porcentajes de participación de CESCE en el riesgo, debido a que el importe medio de las operaciones ha sido menor y también al menor número de operaciones.

La tendencia positiva de las cifras de CESCE contrasta un poco con la registrada por el conjunto de la Unión de Berna, que, en cambio, anota una ligera caída en su actividad. Dicha asociación reúne a las principales aseguradoras mundiales de crédito a la exportación e inversiones, incluidas las principales agencias de crédito a la exportación (ECA, por sus siglas en inglés). Sus miembros, repartidos por todo el mundo, aseguran o prestan en torno a 2 billones de dólares (USD) anuales, cifras que representan aproximadamente el 10 por 100 del comercio mundial. En 2016, las ECA de la Unión de Berna han notificado una cifra global de operaciones menor que la del año anterior y explican esta caída por el retroceso experimentado en los sectores relacionados con los hidrocarburos, los efectos de las sanciones en varios mercados importantes para las ECA, como Rusia o Irán, o la menor actividad de las principales ECA europeas en el sector aeronáutico.

\section{Operaciones aprobadas en 2015}

CESCE publica en su web, con periodicidad anual, un informe en el que figuran los datos de actividad de cada año, tanto por cuenta propia como por cuenta del Estado. De la publicación de 2015 se extrae que, por cuenta del Estado, el seguro emitido total fue de 2.641 millones de euros. No obstante, tomando como referencia únicamente las operaciones individuales, la emisión de seguro ascendió a $\triangleright$ 


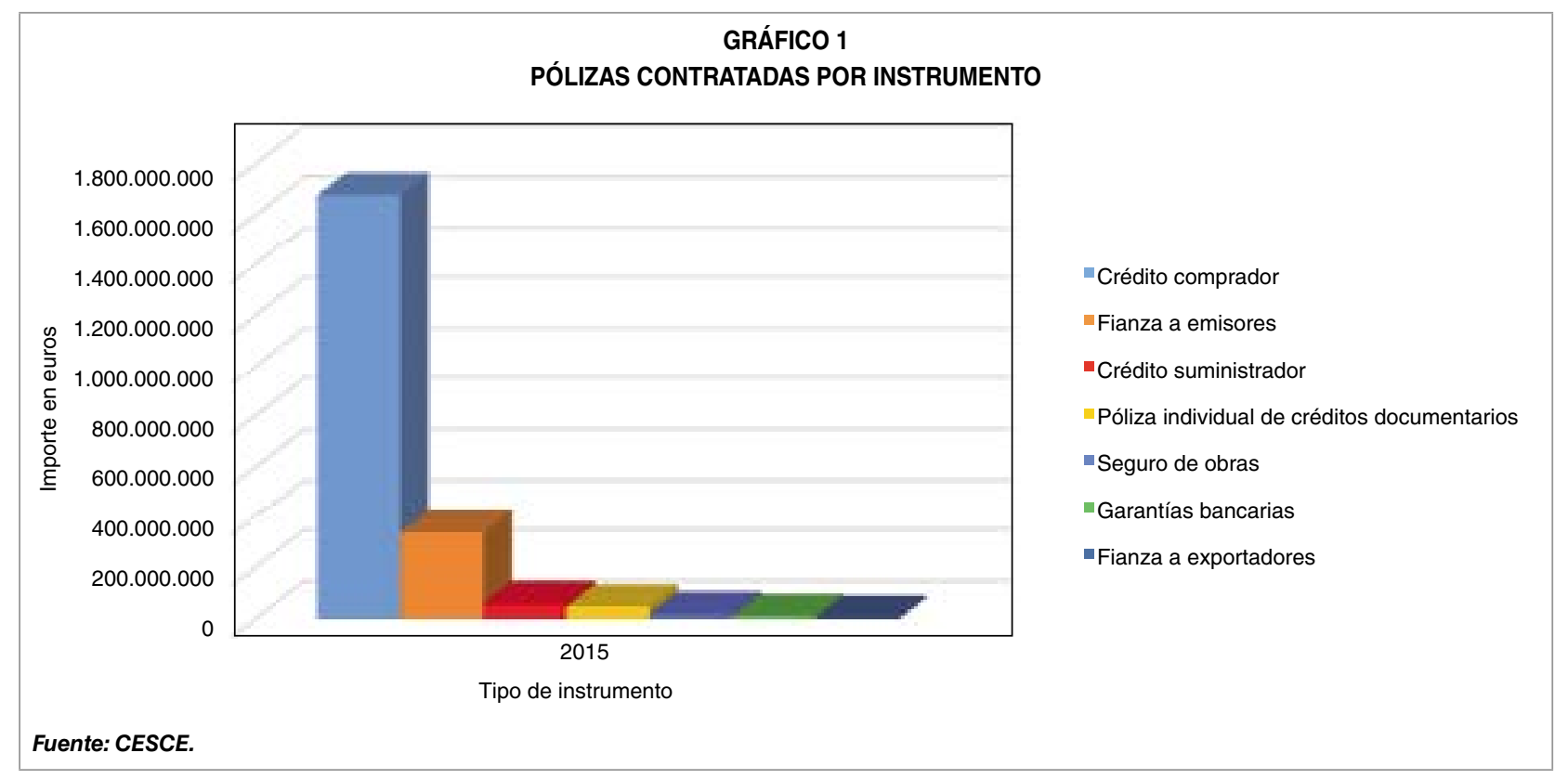

2.006 millones de euros, cifra que es la que se imputa bajo el límite anual que la Ley de Presupuestos Generales del Estado fija para la contratación de nuevas operaciones por cuenta del Estado.

Por contextualizar este dato, cabe señalar que la cifra media de contratación de pólizas individuales durante la primera década del siglo ha estado situada en torno a 1.600 millones de euros. Tras un brusco y efímero aumento durante los años de crisis económica, hasta los 4.000 millones de euros anuales, la contratación de pólizas individuales volvió a partir de 2013 a los niveles medios antes mencionados.

La cifra de contratación en 2015 se situó claramente en el rango superior de las cifras históricas. Por tipo de producto, cabe resaltar la recuperación de la póliza de crédito comprador, que volvió a ser la modalidad más contratada, dejando a los avales en segunda posición.

Los resultados de 2015 -tanto en volumen como en composición - se vieron muy condicionados por la contratación de una operación singular, la cobertura de la financiación de la refinería STAR en Turquía, responsable del
40 por 100 de la contratación total del año, proyecto al que se alude más adelante.

Las primas devengadas para el Estado en 2015 ascendieron a 151 millones de euros, duplicando las del año anterior. Igual evolución siguieron las primas efectivamente cobradas en el ejercicio, que incluyen aquellas contratadas en años anteriores cuyo pago quedó aplazado y se ha recibido este año, que han supuesto 166 millones de euros.

\subsection{Crédito comprador}

Como se decía anteriormente, el crédito comprador ha vuelto a ser el producto más contratado. La cifra de emisión bajo esta modalidad de seguro ha sido de 1.679 millones de euros, un 77 por 100 de toda la contratación bajo póliza individual.

La mitad de lo contratado bajo la modalidad de crédito comprador corresponde a la refinería STAR de Turquía, que sitúa además a este país como primer destino del seguro en 2015. 


\subsection{Póliza de avales}

El seguro a fiadores por riesgo de ejecución de fianzas o avales fue durante la crisis uno de los productos a los que más recurrieron las empresas españolas, siendo la participación de CESCE, en muchas ocasiones, condición sine qua non para la emisión de las garantías necesarias, bien por la situación financiera del ordenante, bien por los importes de las operaciones.

No obstante, la recuperación de las condiciones económicas y financieras permitió una mejora de los balances de las empresas y una mayor predisposición de los bancos a emitir este tipo de avales, reduciéndose el pero a este tipo de coberturas en la actividad de CESCE por cuenta del Estado. Aun así, este producto sigue siendo el segundo más utilizado de los que ofrece CESCE por cuenta del Estado.

La emisión del seguro de fianzas en 2015 ascendió hasta los 342 millones de euros, cifra muy inferior a las que venían registrándose desde el inicio de la crisis. La caída de las cifras de contratación de seguro de fianzas refleja no solo un menor número de operaciones, sino también la contratación de operaciones más pequeñas $\mathrm{y}$, sobre todo, un menor porcentaje de participación de CESCE en los riesgos, que volvió a la norma precrisis, según la cual la cobertura se instrumenta, salvo excepciones, con un reparto al 50 por 100 de los riesgos entre CESCE y los bancos asegurados.

\subsection{Otras modalidades de seguro}

El resto de las modalidades de seguros supusieron una parte residual de la contratación total. La suma de todas las coberturas, con excepción de crédito comprador y fianzas, fue moderada, en concreto de 145 millones de euros, un 7 por 100 del total. Esta cifra se desglosa en coberturas de confirmación de créditos documentarios por valor de 52 millones de euros, poco más de 60 millones bajo crédito suministrador, principalmente a corto plazo, 20 millones bajo obras y 13 bajo garantías bancarias (prefinanciación).

\section{Operaciones aprobadas en 2016}

El conjunto de operaciones de exportación que han contado con el apoyo de CESCE, de acuerdo con el informe anual de actividad de 2016, suma un valor contractual de 3.444 millones de euros. No puede dejar de señalarse que esta es una cifra comparativamente baja, lo cual obedece a dos razones. La principal razón es que, hasta 2014, en este cómputo se incluían todas las operaciones cubiertas a través de pólizas abiertas en las que el riesgo de impago (riesgo comercial) de la operación se cubría por cuenta propia, limitándose la intervención del Estado a la cobertura de los riesgos políticos o extraordinarios. En los primeros meses de 2015 aún se registraron algunas operaciones bajo este sistema de riesgos compartidos entre la cuenta propia y la cuenta del Estado, no así en 2016. La segunda razón es el descenso de las operaciones de avales (fianzas) en las que el apoyo de CESCE suele ser una parte menor (10-15 por 100) de contratos a menudo de gran envergadura. En 2016 esta modalidad ha registrado un descenso significativo, lo que se refleja en una menor cifra del valor de las operaciones.

Por las mismas razones, la cifra de seguro emitido en 2016 ha sido algo menor que en el ejercicio anterior. La eliminación de pólizas $\triangleright$ 


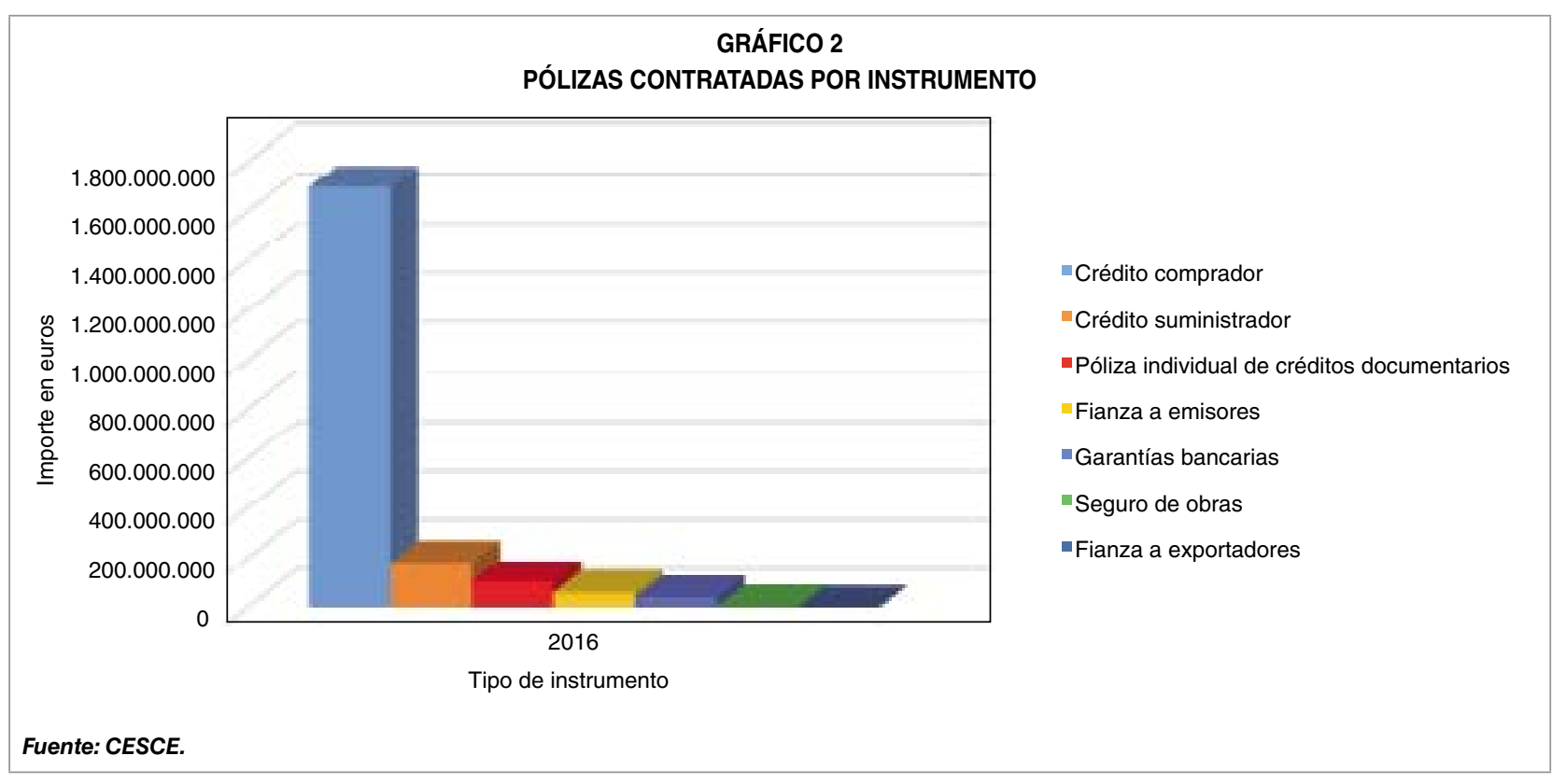

abiertas de corto plazo entre las coberturas ofertadas por cuenta del Estado — que antaño sumaban una media de 3.000 millones de euros anuales a esta partida y en 2015 aún supusieron unos 500 millones de euros-y el descenso de las fianzas hacen que el seguro emitido haya caído en torno a un 21 por 100 respecto al año anterior. En cambio, si tomamos únicamente la cifra de operaciones individuales, la contratación en 2016 ha ascendido a 2.035 millones de euros, muy similar al año anterior. Esta es la cifra que computa en el límite anual que la Ley de Presupuestos Generales del Estado fija para la contratación de nuevas operaciones por cuenta del Estado, actualmente establecida en 9.000 millones de euros anuales.

El volumen de seguro contratado en 2016 se sitúa algo por encima de la media de la década, incluso teniendo en cuenta el incremento que experimentó la contratación durante los años de la crisis. Consolidando la tendencia iniciada el año pasado, la cifra total refleja la recuperación del seguro de crédito comprador, que vuelve a ser la modalidad más contratada, a gran distancia de cualquier otra. Aunque se han asegurado varias operaciones de gran envergadura, por encima de los 200 millones de euros, la contratación ha estado más diluida que otros años entre diferentes proyectos.

Las primas devengadas para el Estado en 2016 han ascendido a 106 millones de euros. Esta cifra supone un descenso del 30 por 100 respecto a 2015. En cambio, es una cifra que se sitúa aproximadamente en un 30 por 100 por encima de la media de los años anteriores a la crisis. Una evolución similar han seguido las primas efectivamente cobradas en el ejercicio, que incluyen aquellas contratadas en años anteriores cuyo pago quedó aplazado y se ha recibido este año, que han supuesto 114 millones de euros.

\subsection{Crédito comprador}

Como mencionamos con anterioridad, la cobertura bajo la póliza de crédito comprador se mantiene como la modalidad más solicitada, confirmando la recuperación del crédito $D$ 
bancario, que ya empezó a observarse en 2015 tras varios años de declive, resultado de la crisis financiera. La cifra de emisión bajo esta modalidad de seguro ha supuesto cerca de 1.700 millones de euros, un 81 por 100 de todo el seguro emitido. Esta cifra, sin llegar a los niveles récord de 2010-2011, se sitúa por encima de la media histórica.

El proyecto singular de mayor envergadura asegurado en este ejercicio ha sido el Metro de Santiago de Chile, en el que CESCE ha participado a través de tres pólizas de crédito comprador, apoyando a las empresas exportadoras españolas CAF, Alstom Transporte e Instalaciones Inabensa. Como proyectos singulares, se puede señalar también la primera fase de la adecuación de la Refinería La Pampilla por Repsol (Perú) o la participación de Elecnor en la central eléctrica de Lauca (Angola).

\subsection{Póliza de avales}

El boom de contratación de seguro por riesgo de ejecución de avales por parte de los emisores registrado durante los años de la crisis ha dado paso a un volumen de contratación más moderado, aunque muy por encima de los niveles precrisis.

Siguiendo una tendencia que ya comenzó el año pasado, la oferta bancaria de este tipo de producto parece cubrir buena parte de la demanda sin necesidad de seguro. $Y$ en los casos en los que participa CESCE se ha establecido como norma la cobertura al 50 por 100 . Cualquier porcentaje superior es ahora mismo una excepción.

Así, la reducción del porcentaje de participación de CESCE y el descenso del número de operaciones y del valor medio de las operaciones aseguradas se han traducido en una cifra de contratación bajo la modalidad de avales de 58 millones de euros, la más baja desde 2007. El importe medio de las operaciones contratadas este año ha sido de 2,3 millones de euros, mucho menor que en años anteriores. Como ilustración de esta circunstancia, el aval más grande asegurado por CESCE ha ascendido a 14 millones de euros y el más pequeño no ha llegado a los 100.000 euros. Otro aspecto relevante de la contratación bajo la modalidad de avales es el hecho de que más de la mitad de las operaciones aseguradas, tanto si se mide en número de operaciones como en cifra de seguro, han sido aprobadas bajo el marco de la línea especial para pymes.

Como se comentará más adelante, la siniestralidad bajo esta modalidad, que tradicionalmente ha sido moderada, aumentó en 2016.

\subsection{Línea pymes de fianzas}

La línea pymes de avales ha sido renovada en 2016, una vez agotado el límite original establecido hace tres años, de 100 millones de euros.

Esta línea está diseñada para ayudar a pequeñas y medianas empresas, así como a empresas de mayor tamaño no cotizadas, a conseguir la emisión de los avales necesarios para poder llevar a cabo su proceso de internacionalización. Tras los primeros años de funcionamiento, se autorizó la inclusión de operaciones de financiación de circulante bajo el paraguas de la línea, con objeto de extender el apoyo no solo a la obtención de avales, sino también a la de capital de trabajo o prefinanciación, no menos crucial para la viabilidad de muchos proyectos. 
Como se decía anteriormente, el límite inicial de 100 millones de euros se ha utilizado casi íntegramente. Algo más de la mitad de las pólizas emitidas han salido ya de riesgo sin que se haya registrado ninguna incidencia de pago. Solo 7 de las 89 operaciones analizadas fueron denegadas.

Buena parte de las empresas que se han beneficiado de esta línea pertenecen al sector de la construcción y actividades relacionadas (servicios técnicos de ingeniería y arquitectura, conservación y mantenimiento de infraestructuras, materiales de construcción, señalización ferroviaria, construcción de infraestructuras de telecomunicaciones y desarrollo de proyectos de infraestructuras llave en mano). Varias empresas pertenecen al ámbito de las energías renovables (servicios de ingeniería, construcción y mantenimiento de proyectos de generación eólica o fotovoltaica, subestaciones, integración fotovoltaica en edificaciones, etcétera).

\subsection{Crédito suministrador}

La contratación bajo la modalidad de crédito suministrador ha sido comparativamente alta en 2016, alcanzando una cifra de suma asegurada de 182 millones de euros, correspondiente a algo más de un centenar de operaciones, casi todas a corto plazo.

En términos del número de operaciones, la mayor parte corresponde a la contratación de riesgos con Cuba. No así si se tiene en cuenta únicamente la cifra de seguro emitido, en la que el peso de Cuba es menor al 10 por 100. Cabe señalar que la asunción de riesgos con este destino se interrumpió a mediados de año debido a la aparición de impagos, en buena parte aún pendientes de solucionar. Por otro lado, varias operaciones han tenido como destino Irán, país que atrae cada vez mayor atención y sobre el que CESCE está recibiendo un número creciente de consultas o solicitudes en firme.

\subsection{Confirmación de créditos documentarios}

La contratación bajo la modalidad de créditos documentarios ha duplicado el nivel registrado el año anterior, alcanzando los 105 millones de euros, la cifra más alta del lustro, aunque aún muy por debajo de niveles históricos. La distribución geográfica de las operaciones aseguradas bajo esta modalidad es muy diversa, con gran predominio de operaciones en Oriente Medio.

Como se comentaba en apartados anteriores, la cobertura bajo la modalidad de créditos documentarios ha mejorado considerablemente al ampliar los riesgos elegibles a riesgos comerciales, que incluyen el riesgo de impago a entidades privadas.

\subsection{Otras modalidades de seguro}

El resto de las modalidades de seguros (inversiones, obras y garantías bancarias) ha supuesto una vez más una parte marginal de la contratación total, superando apenas los 50 millones de euros.

\section{Distribución geográfica en 2015}

Uno de los objetivos prioritarios de la Secretaría de Estado de Comercio, dependiente del Ministerio de Economía, Industria y $\triangleright$ 


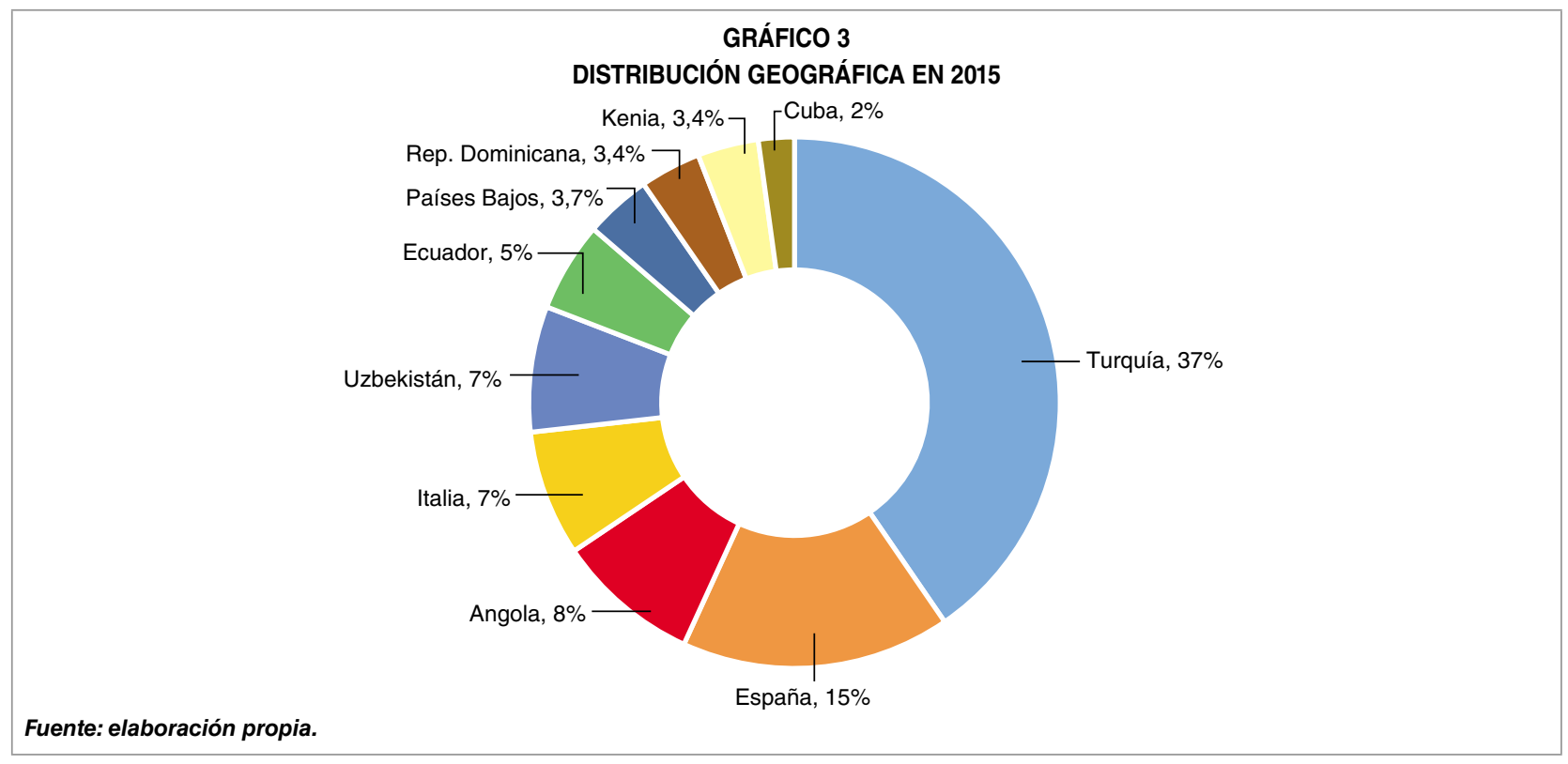

Competitividad, ha sido la diversificación geográfica de las exportaciones españolas. En este sentido, la labor llevada a cabo por CESCE por cuenta del Estado ha contribuido de manera positiva a la consecución de dicho objetivo.

El principal destino del seguro por cuenta del Estado en 2015 fue Turquía, con un 37 por 100 del total, debido a la operación singular de STAR. Muy lejos se situó Angola, segundo país de destino, con un 8 por 100, seguida de Italia, en tercera posición. Uzbekistán ocupó el cuarto puesto, al ser el destino de una venta de aviones de Airbus. Ecuador alcanzó la quinta posición dicho año. Las posiciones 5 a 10 han sido para Países Bajos, República Dominicana, Kenia, Cuba y México.

Un rasgo a destacar de la contratación de 2015 es la realización de varias operaciones de gran envergadura. De hecho, la distribución geográfica refleja, en buena medida, la contratación de operaciones singulares de este tipo. Entre los diez primeros destinos del seguro solo se diversifica la emisión en Angola, Cuba y México. En el resto de los países mencionados, las cifras reflejan la contratación de una única operación.

\section{Distribución geográfica en 2016}

En el año 2016, el principal destino del seguro por cuenta del Estado fue Chile, con un 25 por 100 del total. Como viene siendo habitual, esta primera posición responde a la contratación de una única operación de gran importe, anteriormente mencionada y referida a la venta de material rodante y de instalaciones eléctricas para el Metro de Santiago, en la que han participado las españolas CAF, Alstom e Instalaciones Inabensa. Angola volvió a situarse como segundo destino, con un 19 por 100 del total, a consecuencia de la contratación de varias operaciones importantes, seguido de Perú (14,6 por 100), cuyo protagonismo obedece al aseguramiento de la financiación de la reforma de la Refinería La Pampilla por parte de Repsol.

A gran distancia se colocaron, en cuarta posición, Arabia Saudí, seguida de Omán, $\triangleright$ 


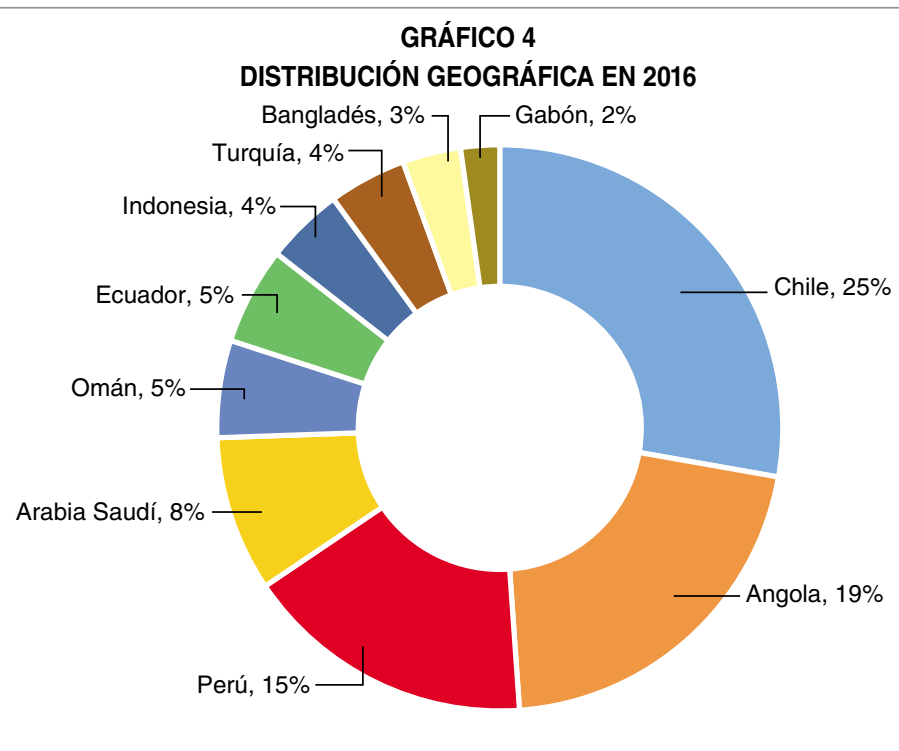

Fuente: elaboración propia.

Ecuador, Indonesia, Turquía, Bangladés y Gabón.

\section{Cartera de riesgos al cierre de $\mathbf{2 0 1 6}$}

Al cierre del ejercicio 2016, el valor de los riesgos en cartera ascendía a 15.436 millones de euros, lo que supone un descenso de un 5 por 100 en relación al año anterior.

El grueso de la cartera sigue correspondiendo a la partida de riesgos vivos en curso (capital comprometido pendiente de vencer), que asciende a casi 13.000 millones de euros, un 8 por 100 menos que en 2015.

Cabe destacar que la refinanciación de la deuda cubana ha permitido poner fin a una situación irregular lastrada desde hace muchos años. En efecto, Cuba firmó los acuerdos multilaterales con el Club de París en 2015. Por su parte, el bilateral con España relativo a la deuda a corto plazo se firmó a finales de ese mismo año, y el bilateral de la deuda a largo plazo, en mayo de 2016.

Desde la óptica de la gestión de la cartera de riesgos, destaca que la distribución tanto por países como por deudores sigue estando diversificada, consolidándose la recuperación del crédito comprador como modalidad más contratada. Este resultado es positivo, ya que, en caso de siniestro, los pagos se diluyen a lo largo de la vida del crédito, que suele ser a largo plazo, a diferencia de otras modalidades en las que la siniestralidad puede ser más inmediata en el tiempo.

Si se mira la foto fija de la cartera de riesgos vivos a 31 de diciembre de 2016, la lista está encabezada por Turquía, con un 12,3 por 100 de los riegos vivos en cartera. Le sigue el riesgo España, partida en la que se apuntan todas las operaciones de crédito comprador en las que el deudor es la filial extranjera de un grupo español o que cuentan con la garantía de una empresa española. También incluye el seguro a emisores de avales y las garantías bancarias (prefinanciación). Lo más destacable es que la cifra de riesgo España pasa de niveles muy bajos a situarse en lo alto de la lista a partir de 2008. Al cierre de 2017 se coloca en segunda posición, con un 11,45 por 100 de la cartera. 


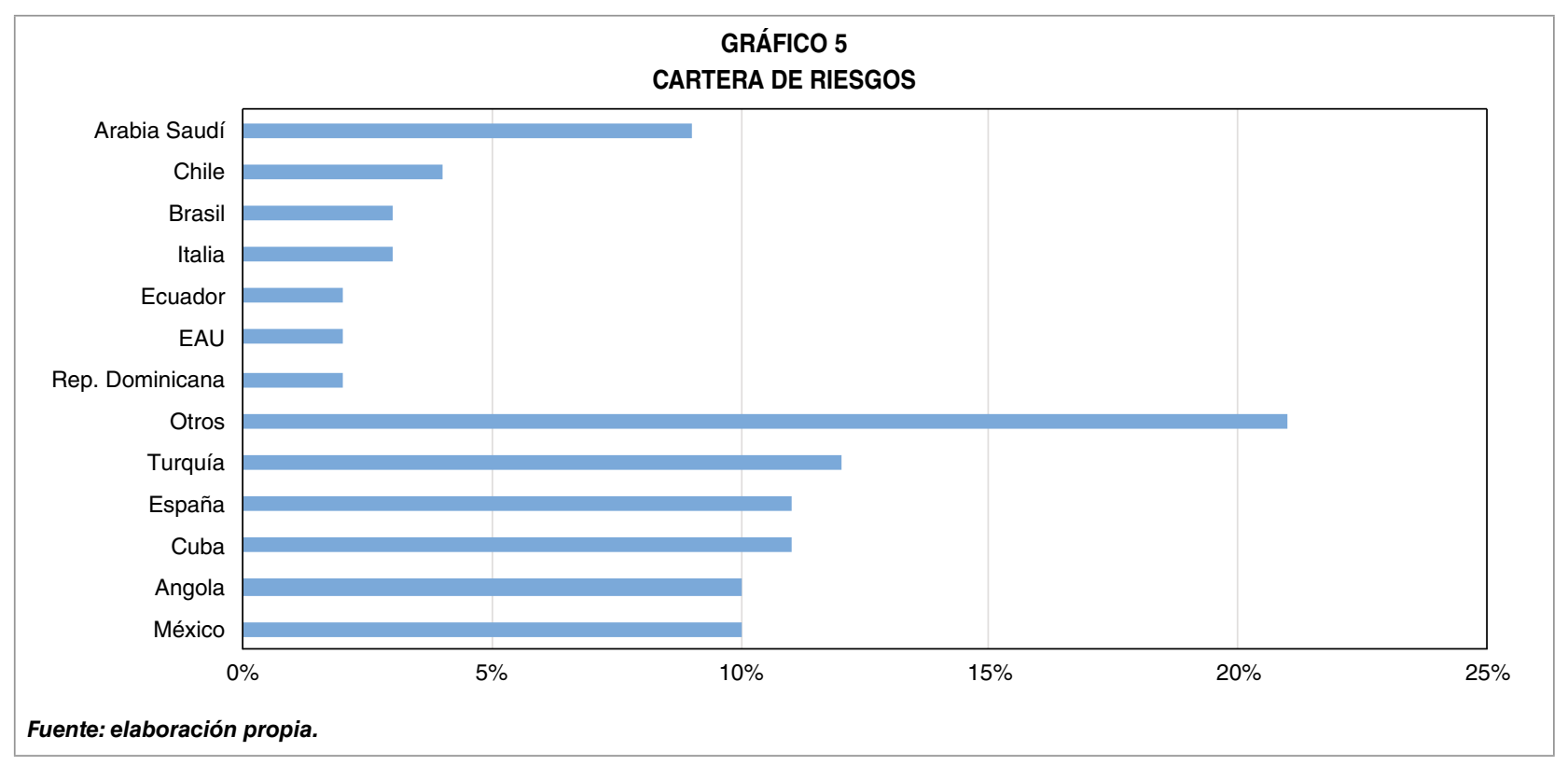

En tercera posición se sitúa Cuba, principalmente por la deuda refinanciada correspondiente a operaciones antiguas. Le siguen Angola, México y Arabia Saudí, cada uno con una cifra cercana al 10 por 100.

Lejos de estos países, aunque con un peso significativo (entre el 4 y el 2 por 100) en la cartera, se colocan, por orden: Chile, Brasil, Italia, República Dominicana, Emiratos Árabes Unidos y Ecuador.

A pesar de que las operaciones con compradores y deudores privados han ganado terreno en los últimos lustros, el riesgo con el sector público sigue siendo predominante en la cartera de CESCE, aglutinando un 62 por 100 de las operaciones de crédito en vigor. En una división entre deudores privados, públicos no soberanos y soberanos, estos últimos son los que mayor peso tienen, con un 39 por 100 del total. Este tipo de riesgo está relativamente concentrado en quince países, encabezados por Angola, República Dominicana, Emiratos Árabes Unidos (principalmente Abu Dabi), Ecuador, Brasil, México, Gabón, Indonesia y Camerún.

\section{Fondo de Reserva de los Riesgos de la Internacionalización de la Economía Española}

La Ley 8/2014, de 22 de abril, sobre cobertura por cuenta del Estado de los riesgos de la internacionalización de la economía española, creó el Fondo de Reserva de los Riesgos de la Internacionalización de la Economía Española (en adelante, FRRI) como mecanismo para la disposición de los recursos económicos que el Estado dedica a la cobertura de dichos riesgos, con un mayor equilibrio financiero y menor impacto presupuestario, y encomienda la gestión y administración del FRRI al Consorcio de Compensación de Seguros (en adelante, CCS), y la cobertura de los riesgos por cuenta del Estado a CESCE, a quién le corresponde la condición de agente gestor del FRRI.

\subsection{Actividad del FRRI}

El FRRI se creó como un fondo de titularidad estatal y sin personalidad jurídica, al $\triangleright$ 
amparo de lo previsto en el artículo 2.2 de la Ley 47/2003, de 26 de noviembre, General Presupuestaria, al que han de imputarse las operaciones de cobertura de los riesgos de la internacionalización de la economía española por cuenta del Estado.

La gestión de estos riesgos la lleva a cabo el agente gestor, que presta los servicios de gestión de los instrumentos de cobertura por cuenta del Estado. Esta función está atribuida a CESCE, debiendo registrar las operaciones que realice por cuenta del Estado en una contabilidad separada e independiente de cualquier otra actividad que realice por cuenta propia.

La gestión y la contabilización de las operaciones financieras del FRRI y la preparación de sus cuentas anuales corresponde al CCS como entidad gestora y administradora del fondo.

\subsection{Régimen jurídico $y$ económico-financiero}

Según establece el artículo 9 de la Ley $8 / 2014$, le es de aplicación al FRRI el régimen presupuestario, económico-financiero, contable y de control previsto en la Ley General Presupuestaria para los fondos carentes de personalidad jurídica, cuya dotación se efectúe mayoritariamente con cargo a los Presupuestos Generales del Estado, a que se refiere el artículo 2.2 de dicha ley.

Integran los recursos del FRRI los derechos económicos y primas ingresadas (una vez deducida la remuneración de CESCE), los recobros de siniestros, las comisiones y eventuales rentas patrimoniales. Adicionalmente, en los Presupuestos Generales del Estado se consignan los créditos para facilitar al FRRI las aportaciones patrimoniales que resulten necesarias para hacer frente a las desviaciones que la cobertura de los riesgos comerciales, políticos y extraordinarios por cuenta del Estado pudiera producir cuando sus recursos acumulados sean insuficientes. El CCS elabora anualmente la propuesta de sus presupuestos de explotación y de capital de acuerdo con lo establecido en el artículo 64 de la Ley General Presupuestaria, a partir de las previsiones remitidas por CESCE.

El resultado del ejercicio 2015 ascendió a 152 millones de euros, mientras que en 2016 el resultado fue ligeramente superior, alcanzando los 164 millones. Estas cifras se explican, en su mayor parte, como consecuencia de los siguientes elementos:

- Primas imputadas al ejercicio, netas de reaseguro. En el ejercicio 2016 se han ingresado de los asegurados primas devengadas por seguro directo por importe de 104 millones de euros (148 millones en 2015), destacando las primas devengadas en las modalidades de crédito comprador por 81 millones de euros y fianzas por 13 millones de euros (125 millones y 21 millones, respectivamente en 2015).

- Ingresos procedentes de las inversiones financieras (refinanciaciones). Fruto de las operaciones de cobertura de riesgos, se han generado en el ejercicio intereses (ingresos financieros) por 33 millones de euros (frente a 31 millones de 2015), a los que habría que añadir ingresos por 351 millones de euros de variación de intereses devengados y no cobrados (explicado principalmente por la firma del convenio de refinanciación de la deuda con Cuba a medio y largo plazo), y 0,6 millones de euros negativos de variación de $\triangleright$ 
intereses devengados y no vencidos, resultando finalmente un ingreso total de 384 millones de euros (81 millones de euros en 2015).

- Siniestralidad del ejercicio, neta de reaseguro. La siniestralidad de 2016 de propia retención es negativa en 24 millones de euros, frente a los 23 millones negativos de 2015. Dicho importe se descompone en los siniestros pagados en el año (102 millones de euros), netos de recobros obtenidos de principal (144 millones de euros), corregidos en la variación habida entre los importes registrados al final y al comienzo del ejercicio por «recobros estimados» de seguro directo y de reaseguro aceptado (22 millones de euros), y en la variación de la «provisión para siniestros pendientes de liquidación y pago» del ejercicio (36 millones de euros), más los gastos imputables a las prestaciones (2 millones de euros).

\subsection{Actuaciones de administración del FRRI}

Los recursos del FRRI se han invertido conforme a los principios de seguridad, rentabilidad, liquidez, diversificación y dispersión y congruencia monetaria, y, en todo caso, de acuerdo al Plan General de Inversiones aprobado por la Secretaría General del Tesoro y Política Financiera a propuesta del CCS, en el que se concretan los parámetros de riesgo asumible y las directrices para la inversión de los recursos del FRRI.

La política monetaria expansiva del Banco Central Europeo (BCE), a través del programa de compra de activos, marcó la evolución de los tipos de interés y del riesgo de crédito en la zona euro durante 2016, dando lugar a un ajuste en los tipos de interés de la deuda, tanto pública como privada, acompañado de un estrechamiento de la prima de riesgo del Bono del Estado español respecto al bund, así como de una reducción general del riesgo de crédito.

La rentabilidad en 2016 de la cartera del FRRI en su conjunto, con una duración financiera de 2,55 años e incluyendo el efecto de los tipos de cambio de las divisas, ha sido del 3,32 por 100.

La cartera de activos en euros, un 61,34 por 100 del total y con una duración financiera de 2,82 años, obtuvo una rentabilidad del 2,52 por 100 , con un diferencial positivo frente al benchmark de 68 puntos básicos.

La denominada en dólares, un 38,66 por 100 del total y con una duración financiera sensiblemente más ajustada de 2,22 años, obtuvo una rentabilidad financiera del 1,38 por 100 (sin considerar el efecto de los tipos de cambio en las divisas), con un diferencial bajo el benchmark de 55 puntos básicos, debido al posicionamiento más conservador ante las expectativas de subida de los tipos de interés en Estados Unidos en los últimos meses del año y que ha sido menor según las previsiones iniciales. $\quad \square$

CUADRO 1

CARTERA DE GESTIÓN VS. BENCHMARK

(Porcentajes)

\begin{tabular}{|l|c|c|c|c|}
\hline \multirow{2}{*}{ Conceptos } & \multicolumn{2}{|c|}{2016} & \multicolumn{2}{c|}{2015} \\
\cline { 2 - 5 } & Euro & USD & Euro & USD \\
\hline $\begin{array}{l}\text { Cartera de } \\
\text { gestión } \\
\text { Benchmark }\end{array}$ & 2,5 & 1,4 & 0,4 & 0,6 \\
\hline
\end{tabular}

1 Se ha tomado como benchmark o índice de referencia para la gestión de la cartera:

- Euro: índice compuesto del BSPS110: deuda pública española con vencimiento 1-10 años; BERC110; deuda corporativa con grado de inversión en euros con vencimiento 1-10 años; y Letras del Tesoro a 6 meses, ajustado a una duración de 3 años.

- Dólares USA: índice compuesto del BUSY35: deuda pública de EEUU con vencimiento 3-5 años, BUSC110; deuda corporativa con grado de inversión en dólares con vencimiento 1-10 años; y Letras del Tesoro americano a 6 meses, ajustado a una duración de 3 años.

Fuente: elaboración propia. 
El valor de la cartera al cierre del ejercicio alcanzó 1.180 millones de euros.

La rentabilidad de los fondos propios o ROE (return on equity), que se utiliza para medir el rendimiento para el Estado de los fondos que destina a la gestión de los riesgos de la internacionalización de la economía española, a través del cociente entre el resultado de la cuenta de pérdidas y ganancias y los fondos propios del FRRI, fue, al cierre del ejercicio, de un 19,08 por 100 .

\section{CUADRO 2}

RENTABILIDAD DE FONDOS PROPIOS O ROE

\begin{tabular}{|l|c|c|}
\hline \multicolumn{1}{|c|}{ Rentabilidad } & $\mathbf{2 0 1 6}$ & $\mathbf{2 0 1 5}$ \\
\hline ROE & $17,5 \%$ & $19,6 \%$ \\
\hline \multicolumn{2}{|l|}{ Fuente: elaboración propia. } \\
\hline
\end{tabular}

CUADRO 3

FONDOS PROPIOS

\begin{tabular}{|l|c|c|}
\hline & Ejercicio 2016 & Ejercicio 2015 \\
\hline Fondos propios & 941.986 .830 & 777.118 .285 \\
I. Patrimonio aportado & 624.734 .398 & 624.734 .398 \\
II. Patrimonio generado & 317.252 .432 & 152.383 .887 \\
\hline \multicolumn{2}{|l|}{ Fuente: elaboración propia. } \\
\hline
\end{tabular}

\section{Conclusiones}

A lo largo de sus más de cuarenta años de historia, CESCE ha cumplido una función clave en el proceso de internacionalización de la economía española al facilitar la captación de recursos por parte de las empresas exportadoras españolas. Este resultado lo ha llevado a cabo, además, conjugando con éxito la difícil doble misión de, por un lado, cubrir un fallo de mercado como asegurador de última instancia $y$, por otro, mantener el equilibrio financiero del propio instrumento.

EI papel de CESCE es especialmente relevante en el nuevo contexto económico en el que el sector exterior se configura como una de las principales locomotoras de crecimiento económico.

La mayor parte de los contratos internacionales exigen hoy en día la presentación de una oferta financiera para el comprador de los bienes y servicios y/o la presentación de garantías que respondan de la seriedad de la oferta en la fase de licitación o negociación, del buen uso del anticipo, del fiel cumplimiento de los términos contractuales, etcétera. Los cambios en la regulación bancaria y la mayor aversión al riesgo por parte de las entidades financieras hace más necesaria que nunca la labor de CESCE para dar tranquilidad y seguridad a los exportadores y financiadores de las operaciones de internacionalización.

En el contexto actual, es imprescindible contar con instrumentos ágiles y flexibles que permitan responder a las necesidades de nuestras empresas y bancos. Para ello, CESCE y la Secretaría de Estado de Comercio siguen revisando los condicionados generales de sus principales seguros. Si el año 2016 fue el turno de la póliza de fianzas, ahora denominada seguro por riesgo de ejecución de avales, en la actualidad ya se han revisado cuatro condicionados y se espera completar la reforma de los mismos en el ejercicio 2018.

Así mismo, en 2016, la Comisión Delegada del Gobierno para Asuntos Económicos (CDGAE) ha dado el visto bueno a la ampliación de la línea para pymes, aprobando un nuevo tramo de 100 millones de euros. Cabe recordar que el ámbito de aplicación de esta línea abarca no solo operaciones de avales, sino también de créditos de prefinanciación o circulante, lo que facilita el acceso a este tipo de financiación a las pymes exportadoras.

En definitiva, se puede destacar que la cobertura de los riesgos de la internacionalización por cuenta del Estado se sigue configurando $\triangleright$ 
como la principal herramienta con la que cuentan nuestros exportadores en su cada vez más relevante camino de internacionalización, especialmente importante cuando se trata de mercados poco maduros, en los que la cobertura de CESCE se hace en ocasiones imprescindible. No obstante, la evolución de los mercados y los cambios en las necesidades obligan a adaptarnos continuamente a las demandas que nos transmiten nuestros exportadores, en las que se pone de manifiesto la importancia de establecer instrumentos específicos para las pymes. Así, si bien desde la modificación del marco regulatorio en 2014 se han logrado avances en respuesta a estas nuevas necesidades, todavía queda un largo camino por recorrer y la Secretaría de Estado de Comercio, en coordinación continua con CESCE como agente gestor, sigue trabajando para hacer de la cobertura por cuenta del Estado un instrumento moderno y ágil que permita apoyar de manera eficaz el proceso de internacionalización que vive la economía española.

\section{Bibliografía}

[1] BERNE UNION (2017). Aggregate Statistics 2016 Year End. Disponible en: http://cdn.berneunion.org/assets/Images/Berne-Union2016-Year-End-Statistics.pdf

[2] CESCE (2016). Informe Anual 2015.

[3] CESCE (2017). Informe Anual 2016. Disponible en: $h$ ttp://www.cesce.es/sites/all/themes/cesce/Docs/Memoria2016/MEMORIA_CESCE INFORME_ACTIVIDADES_Vdef.pdf

[4] SECRETARÍA DE ESTADO DE COMERCIO (2017). Estrategia de Internacionalización de la Economía Española 2017-2027. Disponible en: http://www.mineco.gob.es/stfls/minecol comercio/pdf/170913_Estrategia_Internacionalizacion_2017.pdf 